Abpressen und Auswaschen empfohlen werden, also ein recht langwieriges Verfahren, das auch im Einzelnen nicht einwandfrei ist ${ }^{1}$ ).

Allgemeine Eigenschaften der Fette und Oele. Wie das Fett im menschlichen und thierischen Körper entsteht, ist immer noch nicht klar und sicher erkannt. Aus den Arbeiten von E. Pflüger scheint hevorzugehen, dass die Fette zunächst eine Umwandlung in fettsaure Salze erfahren, wobei die Galle eine wichtige Rolle spielt ${ }^{8}$ ). Die Seifen lösen sich dann unter hydrolytischer Spaltung und werden so resorbirt. Auch nach G. Rosenfeld ist eine Bildung des Körperfettes etwa aus dem Eiweiss der Nahrung nicht nachweisbar, wohl aber ausser der Fettbildung aus Kohlenhydraten die directe $\mathrm{Ab}$. lagerung des Nahrungsfettes ${ }^{1}$ ). Dagegen will A. Zaitschek bei Fütterung von Gänsen mit verschiedenen Fetten keinerlei Veränderung in der Beschaffenheit des Gänsefettes beobachtet haben ${ }^{2}$ ).

(Fortsetzung folgt.)

\title{
Scheidetrichter mit Bürette für Fett- und Seifen-Analysen.
}

\section{Von Ed. Donath.}

Es kommt bekanntlich bei Fett- und Seifenanalysen häufig vor, dass man aus Emulsionen

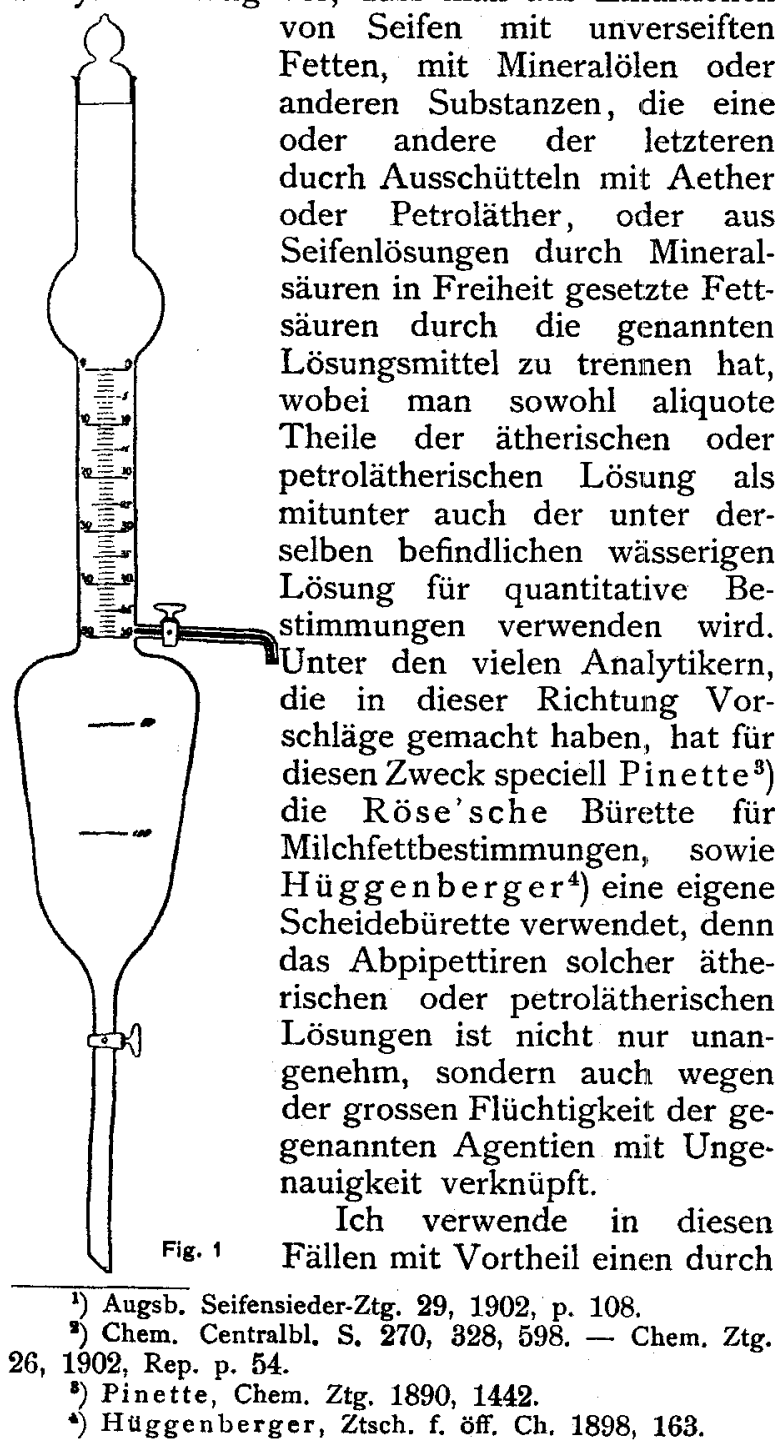

Fig. 1 veranschaulichten Scheidetrichter mit Bürette und seitlichem Abfluss. Der eigentliche Scheidetrichter $S$ fasst $150 \mathrm{ccm}$ und ist mit zwei Marken versehen, um je ein Drittel des Inhaltes abmessend ausfliessen lassen zu können. Die Bürette, in welcher sich nach dem Ausschütteln die ätherische oder petrolätherische Lösung ansammelt, hat einen Durchmesser von $2,5 \mathrm{~cm}$ und ist von $0-50 \mathrm{ccm}$ in einzelne Cubiccentimeter getheilt. Es kann aus derselben durch das etwas über Marke 50 entsprechend angesetzte Hahnrohr mit sehr engem Röhrchen entweder die ganze Lösung (unter Nachspülung mit etwas Aether) oder ein aliquoter Theil abgelassen werden, ohne dass etwas von der wässerigen Lösung mitgeht. Ich selbst habe bisher die Scheidebürette gemäss Fig. 1 verwendet. Will man jedoch auch Theile der wässerigen Lösung für quantitative Bestimmungen genauer abmessen, als dies bei der Weite des Gefässes $S$ möglich ist, so kann man dem Instrument die Form von Fig. 2 geben, bei welchem je $50 \mathrm{ccm}$ mittelst den an den Rohrstücken zwischen den einzelnen Kugeln angebrachten Marken genau abgemessen werden können.

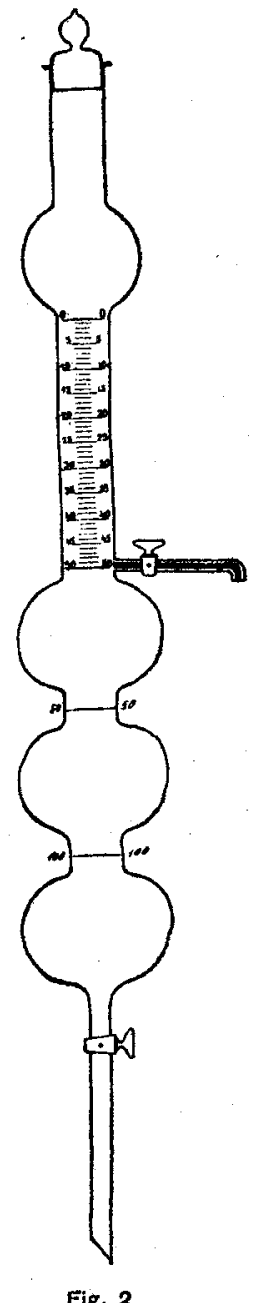

j) Chem. Ztg. 26, 1902, p. 1110 .

2) Ebenda, p. 276 . 